\title{
KONDISI EKOLOGI DAN PEMANFAATAN SUMBERDAYA MANGROVE DI DESA TAROHAN SELATAN KECAMATAN BEO SELATAN KABUPATEN KEPULAUAN TALAUD ${ }^{1}$
}

\author{
Rivay Ontorael ${ }^{2}$, Adnan S Wantasen ${ }^{3}$, Ari B Rondonuwu ${ }^{3}$
}

\begin{abstract}
This study aims to determine the ecological condition of mangrove forests, and the use/utilization of mangrove forests. The method used is method of survey and interview cruising. Ecological data retrieval is done by making transects kuadrant shaped by the size of $25 \times 25 \mathrm{~cm}$ by 3 pieces lengthwise parallel to the coastline of South Tarohan Village. Respondents to the data carried by a purposive sampling interview respondents who have been determined. The results showed that the highest density is owned by Sonneratia alba and the highest frequency is owned by species Sonneratia Alba its index value is also important because it is owned by Sonneratia Alba. Sonneratia Alba is a type of mangrove, Sonneratia which have a dominant role in the mangrove forest ecosystem. Environmental conditions of coastal waters of South Tarohan village has a good environment and support the survival of mangrove forests and biota in the vicinity. South Tarohan Villagers were already aware of and understand the benefits of mangrove forests, it can not guarantee the preservation of mangrove forests because most people still use mangrove wood for household needs for fuel wood.
\end{abstract}

Keywords : Mangrove, ecological

\section{ABSTRAK}

Penelitian ini bertujuan untuk mengetahui kondisi ekologi hutan mangrove, serta penggunaan/pemanfaatan hutăn mangrove. Metode yang digunakan yaitu metode survey jelajah dan wawancara. Pengambilan data ekologi dilakukan dengan membuat transek berbentuk kuadrant dengan ukuran $25 \times 25$ m sebanyak 3 buah memenjang sejajar garis pantai Desa Tarohan Selatan. Untuk data responden dilakukan dengan wawancara secara purposive sampling yaitu responden yang sudah ditentukan. Hasil penelitian menunjukan bahwa Kerapatan jenis tertinggi di miliki oleh Sonneratia alba dan Frekuensi Jenis tertinggi di miliki oleh Sonneratia alba beserta Indeks Nilai Penting juga di miliki oleh Sonneratia alba karena Sonneratia alba merupakan jenis mangrove yang memiliki peranan dominan dalam ekosisten hutan mangrove. Kondisi lingkungan perairan pesisir Desa Tarohan Selatan memiliki lingkungan yang baik dan mendukung kelangsungan hidup dari hutan mangrove dan biota yang ada di sekitarnya. Masyarakat Desa Tarohan Selatan ternyata sudah mengetahui dan memahami manfaat hutan mangrove, hal ini tidak dapat menjamin kelestarian hutan mangrove karena masih sebagian besar masyarakat menggunakan kayu bakau sebagai kebutuhan rumah tangga untuk kayubakar kayu bakar.

Kata kunci : Mangrove, ekologi

\footnotetext{
${ }^{1}$ Bagian dari skripsi

${ }^{2}$ Mahasiswa Program Studi Manajemen Sumberdaya Perairan FPIK-UNSRAT

${ }^{3}$ Staf pengajar Fakultas Perikanan dan IImu Kelautan Universitas Sam Ratulangi
} 


\section{PENDAHULUAN}

Indonesia merupakan negara kepulauan yang terdiri dari 17.504 pulau dengan luas laut sekitar 5,8 juta $\mathrm{km}^{2}$ dan bentangan garis pantai sepanjang 81.000 km (Dahuri et al. 1996). Sebagian besar pulau tersebut merupakan pulau-pulau kecil yang tersebar di seluruh wilayah Indonesia. Pulau-pulau kecil merupakan ekosistem pesisir yang memiliki keunikan dan sumberdaya alam yang spesifik.

Pulau Karakelang merupakan pulau ter-besar di Kabupaten Kepulauan Talaud, Provinsi Sulawesi Utara. Pulau Karakelang memiliki luas $975 \mathrm{~km}^{2}$ yang terbagi atas 6 kecamatan yaitu Kecamatan Melonguane, Kecamatan Beo, Kecamatan Esang, Kecamatan Gemeh, Kecamatan Tampanamma dan Kecamatan Rainis, dan pulau Karekelang juga memiliki sumberdaya alam yang beragam salah satunya yaitu hutan mangrove (BirdLife, 2006).

Luas hutan mangrove yang ada di Desa Tarohan berkisar kurang lebih 20 hektar (Anonimous, 2010). Hutan mangrove memiliki manfaat yang nyata bagi kehidupan, baik manfaat ekologi yaitu sebagai penyedia nutrient bagi biota perairan, tempat pemijahan dan asuhan bagi berbagai macam biota, pena-han abrasi, amukan angin, taufan dan tsunami, penyerap limbah, dan lain sebagainya. Sedangkan manfaat ekonomi dan sosial berfungsi sebagai penyedia kayu, bahan baku obat-obatan dan lain-lain.

Secara umum hutan mangrove diguna-kan untuk kayu bakar dan bahan-bahan bangunan, sehingga hutan mangrove banyak memberikan manfaat yang besar bagi umat manusia, oleh karena itu kita harus menjaga kelestariannya agar ekosistem hutan mangrove tetap berfungsi secara berkelanjutan. Oleh sebab itu ekosistem hutan mangrove harus dikelola dan dimanfaatkan secara berkesinambungan untuk kesejahteraan masyarakat, baik generasi sekarang maupun yang akan mendatang.

\section{METODOLOGI PENELITIAN}

Tempat dan Waktu Penelitian

Pengambilan data dilakukan di Desa Tarohan Selatan Kecamatan Beo Selatan Kabupaten Kepulauan Talaud Provinsi Sulawesi Utara. Waktu penelitian dilaksanakan kurang lebih tiga bulan meliputi penulisan rencana kerja, pengambilan data, analisis data dan laporan hasil.

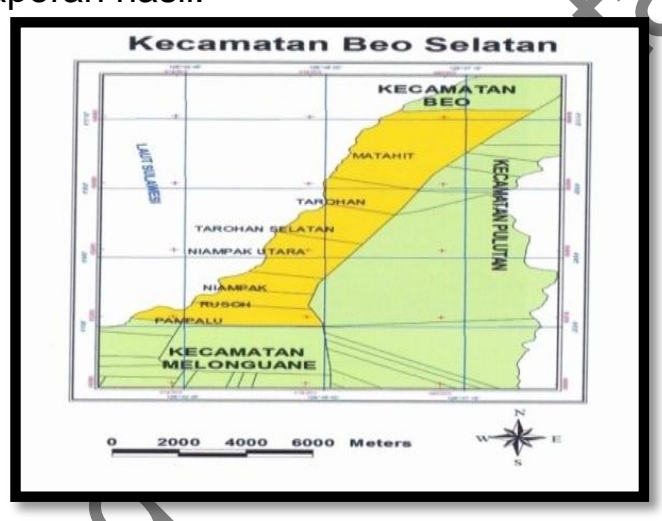

Gambar : 1 Peta Lokasi Penelitian

Metode Pengambilan Data Mangrove Metode yang digunakan dalam penelitian ini menggunakan metode survey jelajah dan wawancara pada responden. Selanjutnya data yang dikumpulkan dalam penelitian ini terdiri dari data primer dan data sekunder.

\section{HASIL DAN PEMBAHASAN}

\section{Kondisi Ekologi Hutan Mangrove}

Pengambilan data yang dilakukan di Desa Tarohan Selatan pada 3 (tiga) stasiun penelitian dengan titik koordinat $04^{\circ} 08^{\prime} 23,5^{\prime \prime}$ LU dan $126^{\circ} 44^{\prime} 54,5^{\prime \prime}$ LS (stasiun 1), $04^{\circ} 08^{\prime} 22,3^{\prime \prime} \quad$ LU dan $126^{\circ} 44^{\prime} 53,4^{\prime \prime}$ LS (stasiun 2), dan $04^{\circ} 08^{\prime} 20,4^{\prime \prime}$ LU dan $126^{\circ} 44^{\prime} 51,4^{\prime \prime}$ LS (stasiun 3).

Berdasarkan hasil identifikasi dan pengamatan di lapangan terhadap vegetasi hutan mangrove yang tumbuh di lokasi penelitian, pada 3 stasiun ditemukan 49 individu dari 3 spesies yang termasuk dalam 3 famili yaitu Avicenniaceae, Rhizophoraceae, dan Sonneratiaceae. Adapun spesies yang di temukan yaitu Avicennia marina, 
Rhizophora mucronata, dan Sonneratia alba.

Menurut Soerinegara dan Indrawan (1980) in Facrul (2007), analisis vegetasi dalam ekologi tum-buhan adalah cara untuk mempelajari struktur vegetasi dan komposisi jenis tumbuhan. Analisis vegetasi bertujuan untuk mengetahui komposisi jenis (su-sunan) tumbuhan dan bentuk (struktur) vegetasi yang ada di wilayah yang di analisis pada setiap stasiun.

\section{Kerapatan Jenis dan Kerapatan Relatif Jenis}

Pada stasiun 1, nilai kerapatan jenis tertinggi terdapat pada spesies Sonneratia alba $\left(0,0176 \mathrm{ind} / \mathrm{m}^{2}\right)$ dengan nilai kerapatan relatif jenis $91,67 \%$, sedangkan terendah yaitu pada spesies Rhizophora mucronata $(0,0016)$ dengan nilai kerapatan relatif jenis $8,33 \%$. Selanjutnya untuk stasiun 2, nilai kerapatan jenis tertinggi dimiliki oleh spesies Sonneratia alba $(0,0176)$ dengan nilai kerapatan relatifnya $68,75 \%$, sedangkan nilai kerapatan terendah dimiliki oleh Rhizophora mucronata $(0,0032)$ dan nilai kerapatan relatif yaitu $12,5 \%$. Sama halnya dengan stasiun 1 dan 2, pada stasiun 3, spesies Sonneratia alba juga yang memiliki nilai kerapatan tertinggi $(0,0208)$ dengan nilai kerapatan relatif $61,90 \%$ sedangkan nilai kerapatan terendah juga terdapat pada spesies Rhizophora mucronata $(0,0048)$ dengan nilai kerapatan relatif $14,29 \%$.

Nilai kerapatan suatu jenis menunjukan kelimpahan jenis dalam suatu ekosistem dan nilai ini dapat menggambarkan bahwa jenis dengan kerapatan tertinggi memiliki pola penyesuaian yang besar. Kerapatan sangat dipengaruhi oleh jumlah ditemukannya spesies dalam daerah penelitian. Semakin banyak suatu spesies, maka kerapatan relatifnya semakin tinggi. Dari perbandingan pada ketiga stasiun penelitian didapati spesies Sonneratia alba memiliki nilai kerapatan tertinggi, hal itu disebabkan karena habitat yang cocok dan kemampuan mangrove dalam beradaptasi pada lingkungan, sedang- kan nilai kerapatan relatif terendah ditempati oleh spesies Rhizophora mucronata.

\section{Frekuensi Jenis dan Frekuensi Relatif Jenis}

Pada stasiun 1 frekuensi kehadiran terbanyak diperoleh Rhizophora mucronata dan Sonneratia alba yaitu 1,5 dengan nilai frekuensi relatif $33 \%$. Pada stasiun 2, diperoleh Rhizophora mucronata dan Sonneratia alba yaitu dengan nilai frekuensi relatif $37 \%$, Pada stasiun 3, diperoleh Rhizophora mucronata dan Sonneratia alba yaitu 1 dengan nilai frekuensi relatif sebesar $37 \%$, sedangkan frekuensi terendah juga dimiliki oleh spesies Avicennia marina $(0,67)$ dengan nilai frekuensi relatifnya $25 \%$ (pada stasiun 2 dan 3 ).

Menurut Fachrul (2007) frekuensi merupakansalah satu parameter vegetasi yang dapat menunjukan pola distribusi atau sebaran jenis tumbuhan dalam ekosistem atau memperlihatkan pola distribusi tumbuhan. Nilai frekuensi dipengaruhi oleh nilai petak dimana ditemukannya spesies mangrove. Makin banyak jumlah kuadran ditemukannya jenis mangrove, maka nilai frekuensi kehadiran jenis mangrove semakin tinggi. Dari ketiga stasiun penelitian Rhizophora mucronata dan Sonneratia alba memiliki nilai frekuensi tertinggi karena memiliki jumlah yang lebih banyak dibandingkan dengan spesies Avicennia marina dan kedua spesies ini terdistribusi merata disetiap kuadran. Frekuesi kehadiran terendah dimiliki oleh Avicennia marina disebabkan karena jenis Avicennia marina tidak terdistribusi merata dan hanya terdapat pada satu kuadran saja. Spesies Rhizophora mucronata dan Sonneratia alba merupakan spesies yang memiliki frekuensi tertinggi hal itu dilihat dari frekuensi kehadiran dari kedua spesies tersebut yang terdistribusi merata disetiap stasiun. Kondisi tersebut terjadi karena spesies ini menyukai daerah pasir berlumpur seperti daerah yang dilokasi penelitan yang memiliki substrat pasir berlumpur (Nybakken,1998). 


\section{Indeks Nilai Penting}

Berdasarkan analisis yang dilakukan didapati indeks nilai penting tertinggi pada ketiga stasiun ditemukan pada spesies Sonneratia alba sebesar $125 \%$, sedangkan nilai indeks penting terendah pada Rhizophora mucronata sebesar $41,66 \%$. Bengen (2000) mengemukakan bahwa besarnya indeks nilai penting berkisar $0-300 \%$, semakin besar nilai indeks penting berarti spesies yang bersangkutan berperan semakin besar dalam komunitas tersebut. Berdasarkan indeks nilai penting yang diperoleh, jelaslah bahwa Sonneratia alba merupakan jenis mangrove yang memiliki peranan dominan dalam ekosistem hutan mangrove di lokasi penelitian.

\section{Variabel Lingkungan}

Menurut FAO (1982) faktor-faktor lingkungan yang mempengaruhi pertumbuhan hutan mangrove di suatu lokasi yaitu: suhu, salinitas dan substrat. Berdasarkan hasil pengukuran salinitas pada setiap stasiun 1,2 dan 3 diperoleh hasil rata-rata $20-39 \%$. Budiman dan Suhardjono (1992) mengatakan bahwa salinitas yang baik untuk pertumbuhan mangrove yaitu sekitar $20-40 \%$, dan berpengaruh besar terhadap distribusi mangrove serta kehidupan fauna akuatik yang hidup disekitarnya. Hasil pengukuran suhu pada stasiun 1,2 dan 3 diperoleh kisaran $30-35^{\circ} \mathrm{C}$, dimana suhu berperan penting dalam proses fisiologis (fotosintesis dan respirasi) produksi daun baru (Bengen, 2000). Pengamatan súbstrat dilakukan secara visual dengan cara meraba tekstur substrat pada setiap stasiun ternyata jenis substrat yang terdapat di lokasi penelitian yaitu substrat batu berpasir. Substrat berperan sebagai endapan yang merupakan salah satu penyebab terbentuknya zonasi dan penyebaran mangrove.

Berdasarkan hasil pengukuran variabel lingkungan di lokasi penelitian menunjukkan kondisi lingkungan perairan pesisir Desa Tarohan Selatan Kecamatan Beo Selatan Kabupaten
Kepulauan Talaud ini memiliki kondisi lingkungan yang baik dan mendukung kelangsungan hidup dari hutan mangrove dan biota yang ada di sekitarnya.

\section{Kegiatan Masyarakat Terhadap Pemanfaatan Hutan Mangrove}

Berdasarkan hasil penelitian terhadap kondisi masyarakat, diperoleh hasil yang menunjukkan masyaraka sudah mengetahui dan memahami manfaat hutan mangrove, walaupun masih ada sebagian masyarakat yang tetap melakukan penebarigan pohon mangrove untuk dimanfaatkan sebagai keperluan kayu bakar, karena kondisi ekonomi mereka (ketidak mampuan membeli minyak tanah), serta akses untuk mengambil kayu bakar dari hutan mangrove sangat mudah (dekat dengan pemukiman), dibandingkan dengan mengambil kayu bakar di hutan yang jauh dari pemukiman.

\section{KESIMPULAN}

1. Kerapatan jenis tertinggi di miliki oleh Sonneratia alba dan frekuensi jenis dan indeks nilai penting tertinggi di miliki oleh Sonneratia alba sehingga Sonneratia alba merupakan jenis mangrove yang memiliki peran dominan dalam ekosistem hutan mangrove. Kondisi lingkungan perairan pesisir Desa Tarohan Selatan dikategorikan baik dan mendukung kelangsungan hidup hutan mangrove dan biota yang ada di sekitarnya.

2. Pemahaman masyarakat akan pentingnya ekosistem mangrove masih lemah di Desa Tarohan Selatan, berdasarkan tingginya tingkat pemanfaatan mangrove sebagai kayu bakar.

\section{DAPTAR PUSTAKA}

Anonimous, 2010, Profil Desa Tarohan Selatan, Kecamatan Beo Selatan Kabupaten Kepulauan Talaud. 
BirdLife, 2006. Pulau Karakelang, Surga Kecil Keanekaragaman Hayati Talaud. Bogor Indonesia.

Bengen D. 2000. Ekosistem dan Sumberdaya Alam Pesisir dan Laut (Sinopsis). Pusat Kajian Sumberdaya Pesisir dan Lautan. Institut Pertanian Bogor.

Budiman dan Soehardjono. 1992. Penelitian hutan mangrove di Indonesia. Pendayagunaan dan konservasi. Lokakarya nasional. Penyusunan Program penelitian biologi kelautan dan proses dinamika pesisir. Puslitbang Biologi. LIPI.
Dahuri R, J. Rais, S.P. Ginting, M.J. Sitepu. 1996. Pengelolaan Sumber Daya Wilayah Pesisir Dan Lautan Secara Terpadu. PT Pradnya Paramita. Hal, 300.

Fachrul, M. F. 2007. Metode Sampling Bioekologi. Bumi Aksara. Jakarta.

FAO. 1982. Management and Untilization of Mangrove in Asia and The Pasific. F.A.O Enviroment Pape.

Nybakken J. 1998. Biologi Laut; suatu pendekatan ekologis. Penerbit Gramedia-Jakarta. 459 hal.

Tabel 1. Data hasil analisis vegetasi hutan mangrove pada setiap stasiun pengamatan

\begin{tabular}{|c|c|c|c|c|c|c|c|c|}
\hline Stasiun & Jenis & $\sum$ Individu & Di & & $\mathbf{F i}$ & RFi & INP & DB \\
\hline \multirow{2}{*}{1} & S. alba & 11 & 0,0176 & 91,67 & 1,5 & 33 & 125,00 & 39 \\
\hline & R.mucronata & 1 & 0,0016 & 8,33 & 1,5 & 33 & 41,66 & 32 \\
\hline \multirow{3}{*}{2} & S. alba & 11 & 0,0176 & 68,75 & 1,0 & 37 & 106,20 & 44 \\
\hline & R.mucronata & 2 & 0,0032 & 12,50 & 1,0 & 37 & 49,95 & 35 \\
\hline & A. marina & 3 & 0,0048 & 18,75 & 0,67 & 25 & 100,75 & 54 \\
\hline \multirow{3}{*}{3} & S. alba & & 0,0208 & 61,90 & 1,0 & 37 & 107,35 & 41 \\
\hline & R.mucronata & & 0,0048 & 14,29 & 1,0 & 37 & 51,74 & 31 \\
\hline & A. marina & 5 & 0,0080 & 23,81 & 0,67 & 25 & 66,26 & 33 \\
\hline
\end{tabular}

Sumber : Data Primer dan Analisis Data, 2012

\section{2}

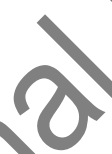

Tabel 2. Hasil Pengukuran Rata-rata Variabel Lingkungan

\begin{tabular}{|l|c|c|c|}
\hline $\begin{array}{c}\text { Parameter } \\
\text { Lingkungan }\end{array}$ & Stasiun 1 & Stasiun 2 & Stasiun 3 \\
\hline Salinitas & $39 \% \circ$ & $40 \% \circ$ & $20 \% \circ$ \\
\hline Suhu & $31^{0} \mathrm{C}$ & $35^{\circ} \mathrm{c}$ & $34^{\circ} \mathrm{c}$ \\
\hline Substrat & Batu berpasir & Batu berpasir & Batu berpasir \\
\hline
\end{tabular}

